\title{
Energetics of lower tropospheric planetary waves over mid latitudes: Precursor for Indian summer monsoon
}

\author{
S M Bawiskar*, M D Chipade, P V Puranik and U V Bhide \\ Indian Institute of Tropical Meteorology, Dr. Homi Bhabha Road, Pune 411 008, India. \\ *e-mail: bawiskar@hotmail.com
}

\begin{abstract}
Based on NCEP/NCAR reanalysis data, kinetic energy and momentum transport of waves 0 to 10 at $850 \mathrm{hPa}$ level are computed from monthly mean zonal $(u)$ and meridional $(v)$ components of wind from equator to $90^{\circ} \mathrm{N}$. Fourier technique is used to resolve the wind field into a spectrum of waves. Correlation analysis between All India Seasonal Monsoon Rainfall (AISMR) and energetics of the waves indicates that effective kinetic energy of waves 1,3 and 4 around $37.5^{\circ} \mathrm{N}$ in February has significant correlation (99.9\%) with the subsequent AISMR. A simple linear regression equation between the effective kinetic energy of these three waves and AISMR is developed. Out of 47 years' (1958-2004) data, 32 years (1958-1989) are utilized for developing the regression model and the remaining 15 years (1990-2004) are considered for its verification. Predicted AISMR is in close agreement with observed AISMR. The regression equation based on the dynamics of the planetary waves is thus useful for Long Range Forecasting (LRF) of AISMR. Apart from the regression equation, the study provides qualitative predictors. The scatter diagram between AISMR and effective kinetic energy of waves 1,3 and 4 around $37.5^{\circ} \mathrm{N}$ indicates that if the kinetic energy is more (less) than $5 \mathrm{~m}^{2} \mathrm{~s}^{-2}$, the subsequent monsoon will be good (weak). Stream function fields indicate that high latitude trough axis along $40^{\circ} \mathrm{E}\left(70^{\circ} \mathrm{E}\right)$ leads to a good (weak) monsoon over India.
\end{abstract}

\section{Introduction}

Indian summer monsoon is a component of global circulation and not a local phenomenon. It interacts in significant ways with other components of global circulation. Global circulations have wavelike features and their characteristics can be studied through their amplitude and phase. The Fourier technique provides the easiest method to compute amplitude and phase of a wave. Its main advantage is that the observed field gets resolved into independent components which are called waves or scales in space domain. This technique has been used by many research workers for diagnostic and prognostic aspects of Indian summer monsoon. Krishnamurti and Kanamitsu (1981) found that wave 3 acts as a source (sink) of kinetic energy during good (drought) monsoon years. Bawiskar et al (2002a) showed that transport of westerly momentum of waves 0,1 and 2 have significant correlation with all India summer monsoon rainfall on a weekly scale. Bawiskar et al (2002b) found that the northward (southward) momentum transport by wave 0 over southern equatorial belt during March leads to a normal (drought) monsoon season over India. Bawiskar et al (2005a) observed that the amplitude of wave 1 was half during 2002 (a drought monsoon year) as compared to that during 1997 (a normal monsoon year). In the same study they have stated that the significant release of kinetic energy by wave 1 might have played a vital role in triggering six intense systems during 1997, whereas the weak supply of kinetic energy might have failed to trigger even a single system during 2002. Bawiskar et al (2005b) found that intensification (weakening) of extra tropical wave 0 and waves 3-10 leads to weak (active) spells of rainfall over India. The above studies clearly

Keywords. Zonal waves; kinetic energy; momentum transport. 
show that the resolution of wind field into wave number domain has revealed many important relations between energetics of zonal waves and Indian monsoon. In the present study, an attempt is made to extend the wave analysis technique to seasonal forecasting of Indian summer monsoon. We have mainly concentrated on the lower tropospheric energetics of zonal waves during winter months (January and February) over northern hemisphere and their impact on the performance of subsequent Indian monsoon season.

\section{Data and methodology}

NCEP/NCAR monthly mean wind components $(u$ and $v$ ) and temperature from equator to $90^{\circ} \mathrm{N}$ for the months of January and February for the years from 1958 to 2004 at $850 \mathrm{hPa}$ level are utilized. All India Seasonal Monsoon Rainfall (AISMR) data for the above period is obtained from the website www.tropmet.res.in of the Indian Institute of Tropical Meteorology.

The methodology relating to Fourier technique and its application for the computation of kinetic energy and momentum transport of the waves is given in detail by Bawiskar and Singh (1992).

\section{Results and discussions}

The wind data are subjected to Fourier analysis. Fourier coefficients are used to compute kinetic energy and momentum transport of the waves. Bawiskar (2003) showed that more than eighty per cent of variance is explained by first ten waves. Therefore, kinetic energy and momentum transport of waves $0-10$ are computed for January and February.

Out of 47 years (1958-2004) data, 32 years (1958-1989) are utilized for developing the regression model and the remaining 15 years (1990-2004) are considered for its verification.

\subsection{Correlation analysis}

It is found that the kinetic energy of waves 1,3 and 4 around $37.5^{\circ} \mathrm{N}$ for the month of February have significant correlation with AISMR. Hence, the results relating to the energetics of waves 1-4 for February are presented and discussed.

In figure 1, latitudinal variation of the correlation coefficient between AISMR and kinetic energy of waves 1 to 4 for February is shown. It can be seen from the figure that the waves 1 and 3 cross the line of $99 \%$ level of significance between $30^{\circ} \mathrm{N}$ and $40^{\circ} \mathrm{N}$. Wave 1 even crosses the line of $99.9 \%$ level of significance. It is also found that effective

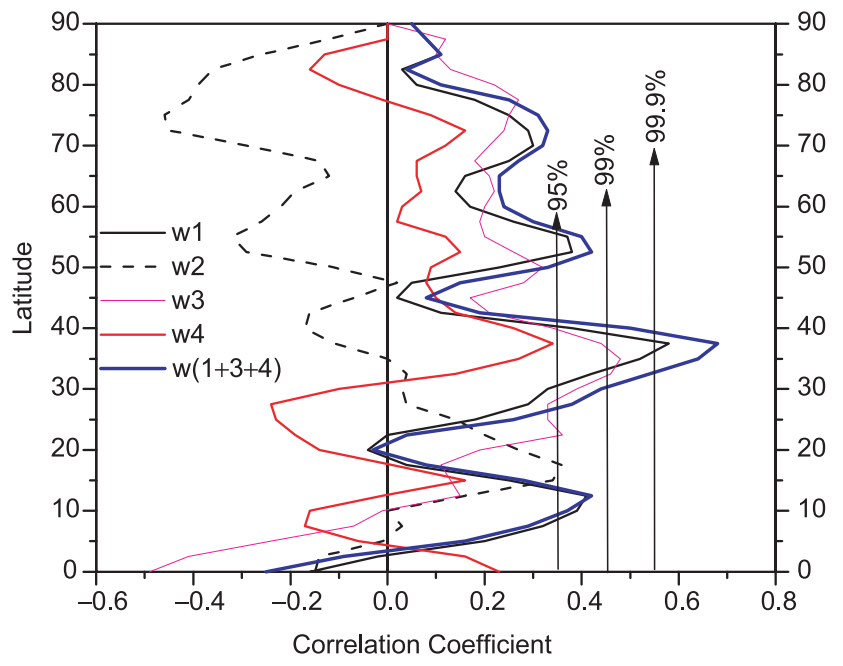

Figure 1. Latitudinal variation of correlation coefficient between AISMR and kinetic energy of waves $1-4$ and $1+3+4$ at $850 \mathrm{hPa}$ for February.

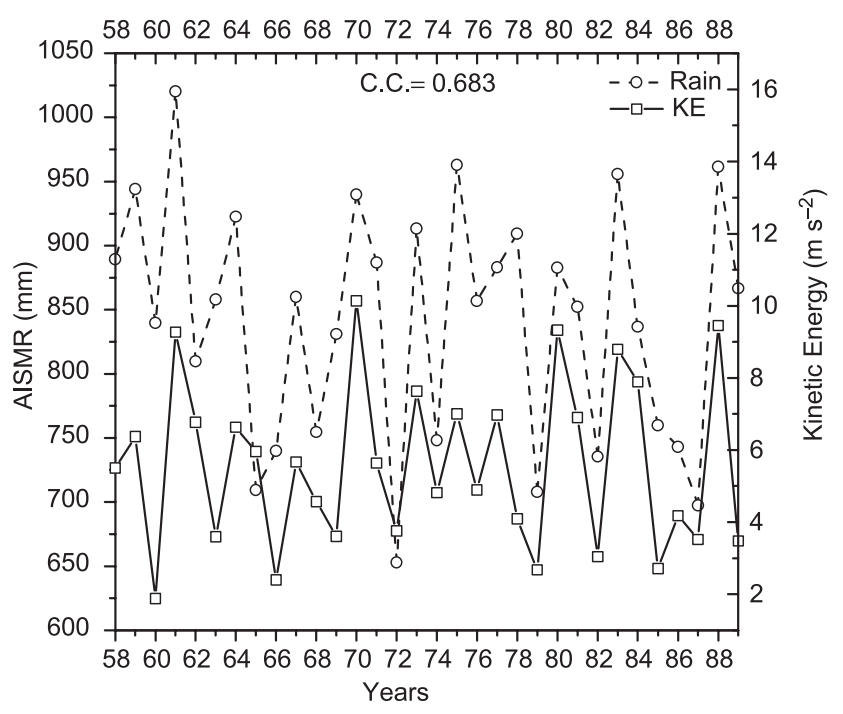

Figure 2. Comparison of AISMR and effective kinetic energy of waves 1,3 and 4 around $37.5^{\circ} \mathrm{N}$ at $850 \mathrm{hPa}$ for February.

kinetic energy of waves 1,3 and 4 shows better relationship than the individual waves which is also presented in figure 1.

Figure 2 gives the inter-annual (1958-1989) variations of AISMR and effective kinetic energy of waves 1,3 and 4 around $37.5^{\circ} \mathrm{N}$. The inter-annual variations of both the series are almost in phase. The correlation coefficient between these two series is 0.683 which is significant at $99.9 \%$ level. The trend of both the series in figure 2 is found to be insignificant.

\subsection{Regression equation}

Figure 3 gives a scatter diagram between AISMR and effective kinetic energy of waves 1,3 and 4 . 


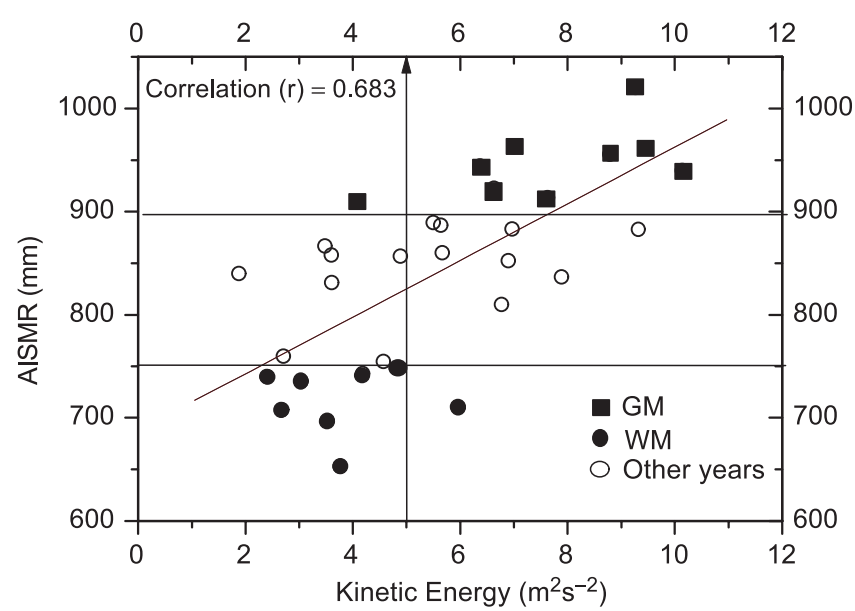

Figure 3. Scatter diagram between AISMR and effective kinetic energy of waves 1,3 and 4 around $37.5^{\circ} \mathrm{N}$ at $850 \mathrm{hPa}$ for February.

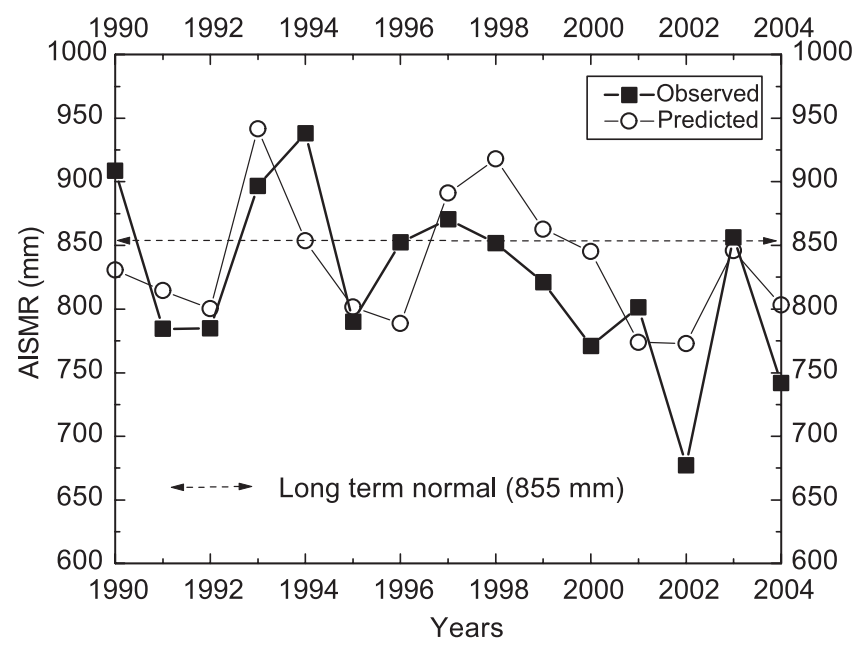

Figure 4. Verification of the performance of regression equation.

The years marked as solid circles are considered for composite of weak monsoon years (WM) and the years marked as solid squares are considered for composite of good monsoon years (GM). The scatter diagram further indicates that most of the good (weak) monsoon years have kinetic energy more (less) than $5 \mathrm{~m}^{2} \mathrm{~s}^{-2}$. A simple regression equation based on these series is given below:

$$
\operatorname{AISMR}=a+b x
$$

where, $a=687.9, b=27.5$ and $x$ is effective kinetic energy of waves 1,3 and 4 around $37.5^{\circ} \mathrm{N}$.

Comparison of the estimated and observed AISMR for fifteen years (1990-2004) is presented in figure 4 and table 1 . It can be seen that both the series are in close agreement. The horizontal line at $855 \mathrm{~mm}$ is the long term normal of AISMR. Most importantly, the negative departures
Table 1. Verification of the performance of the regression equation.

\begin{tabular}{lcc}
\hline & \multicolumn{2}{c}{ Rainfall $(\mathrm{mm})$} \\
\cline { 2 - 3 } Year & Predicted $(\mathrm{P})$ & Observed $(\mathrm{O})$ \\
\hline 1990 & 830.7 & 908.7 \\
1991 & 800.2 & 784.6 \\
1992 & 941.6 & 784.9 \\
1993 & 853.6 & 896.7 \\
1994 & 801.6 & 938.1 \\
1995 & 788.5 & 790.3 \\
1996 & 891.1 & 852.4 \\
1997 & 918.0 & 870.6 \\
1998 & 862.8 & 851.7 \\
1999 & 845.2 & 821.1 \\
2000 & 773.8 & 771.0 \\
2001 & 773.0 & 801.2 \\
2002 & 845.9 & 677.1 \\
2003 & 803.4 & 856.4 \\
2004 & B & 742.0 \\
\hline
\end{tabular}

$\mathrm{RMS}=62.2 \mathrm{~mm}, \quad \mathrm{BIAS}=19.1 \mathrm{~mm}, \quad \mathrm{ABSE}=50.2 \mathrm{~mm}$, $\mathrm{CC}=0.6$.

of AISMR from the normal are very well captured by the regression equation. Root Mean Square Error (RMS) and Absolute Error (ABSE) are $62.2 \mathrm{~mm}$ and $50.2 \mathrm{~mm}$ respectively which are less than the standard deviation of AISMR $(92.8 \mathrm{~mm})$.

\subsection{Physical linkage between the two series}

To identify the physical linkage between the two series, the circulation patterns of composites of good monsoon years (GM) and weak monsoon years (WM) are compared. Stream function $(\psi)$ gives the features as well as the quantitative strength of the circulation pattern. Figure 5 presents $\psi$ fields for GM and WM along with their $t$-statistic. The shaded area (negative $\psi$ ) represents cyclonic curvature or trough while the unshaded area (positive $\psi$ ) represents anti-cyclonic curvature or ridge. There is a significant contrast in the position and strength of high latitude trough for GM and WM. The trough in GM chart is weak and the axis is along $40^{\circ} \mathrm{E}$ whereas the trough in WM chart is not only strong but also extends eastward as well as southward with its axis along $70^{\circ} \mathrm{E}$. Similar features of high latitude trough (ridge) during winter before weak (good) monsoon situation are observed by Meehl (1994a). Kripalani and Kulkarni (1999) have also noted an anomalous cyclonic (anticyclonic) circulation over north Asia during winter prior to a weak (strong) summer monsoon.

Light (dark) grey shading in the last panel of figure 5 illustrates the significance of the difference at 95 (99)\% level as determined from student's $t$-test. The figure indicates that more than $90 \%$ of the area between longitudes $60^{\circ} \mathrm{E}$ to $140^{\circ} \mathrm{E}$ 


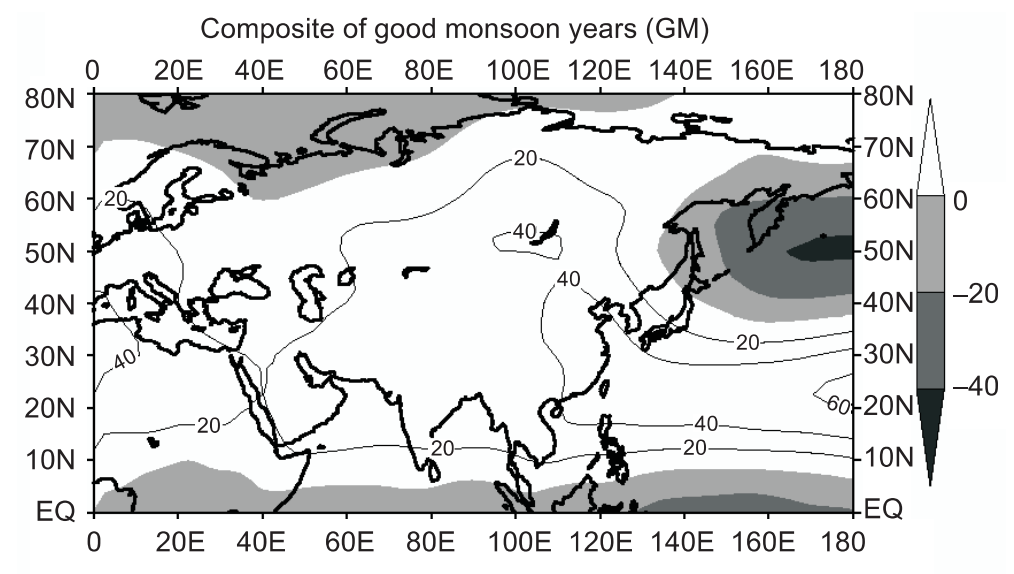

Composite of weak monsoon years (WM)

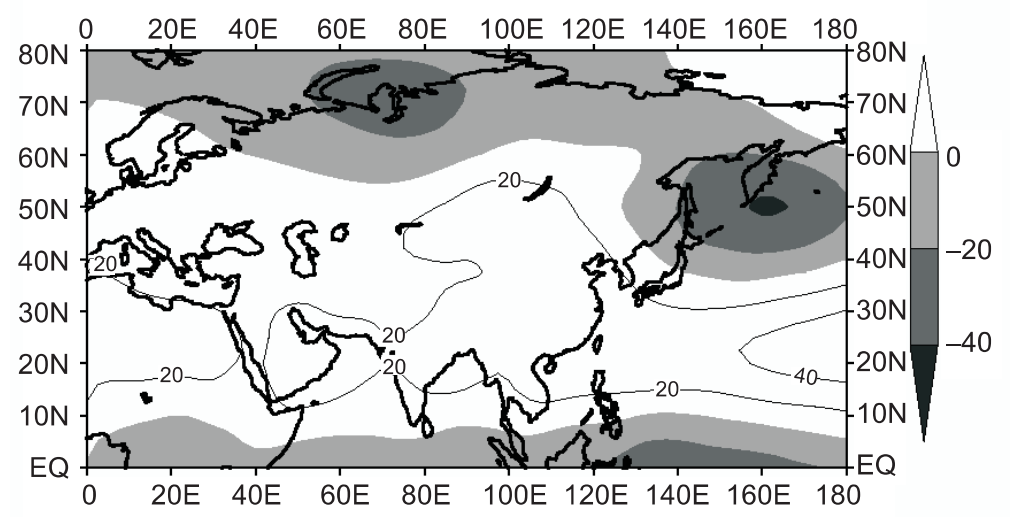

t-statistic

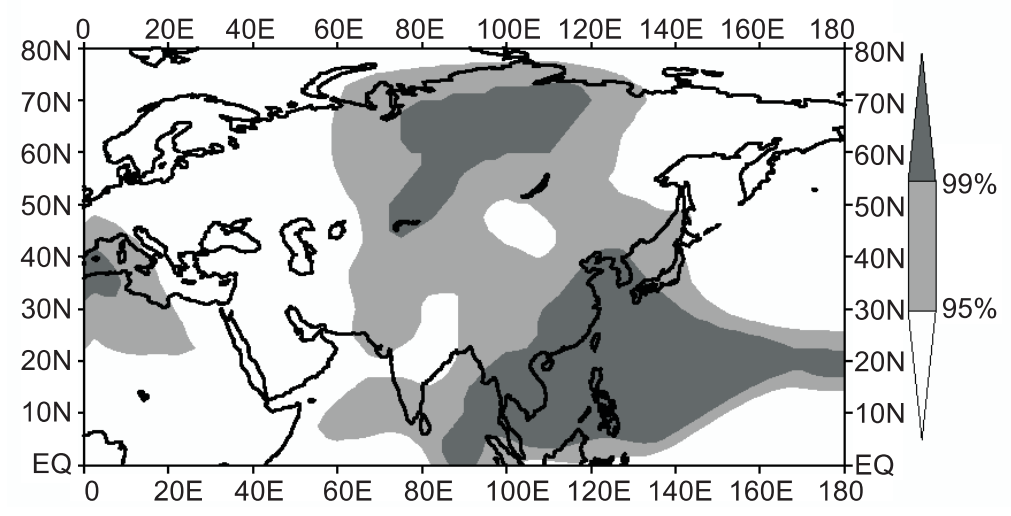

Figure 5. Stream function fields for GM and WM and their $t$-statistic at $850 \mathrm{hPa}$ for February (unit: $10^{6} \mathrm{~m}^{2} \mathrm{~s}^{-2}$ ).

and latitudes 0 to $80^{\circ} \mathrm{N}$ is statistically significant. This region includes the circulations over the mid latitudes where the correlation between AISMR and energetics of planetary waves is significant.

How does the eastward and southward extension of the trough at high latitudes influence the performance of the subsequent monsoon? The west (east) side of the trough causes southward (northward) advection of cold (warm) air. Therefore, when the trough axis shifts from $40^{\circ} \mathrm{E}$ to $70^{\circ} \mathrm{E}$, northward advection of warm air over the area east of $40^{\circ} \mathrm{E}$, will be replaced by southward advection of cold air. This can be verified from meridional wind field.

\subsection{Meridional wind field}

Figure 6 gives meridional $(v)$ wind fields for GM and WM. The shaded (unshaded) area represents southward (northward) component of the wind. The $t$-statistic is also given in the last panel. If we concentrate on the trough region, we find that positive $v$ (northward) between $40^{\circ} \mathrm{E}$ and $70^{\circ} \mathrm{E}$ 


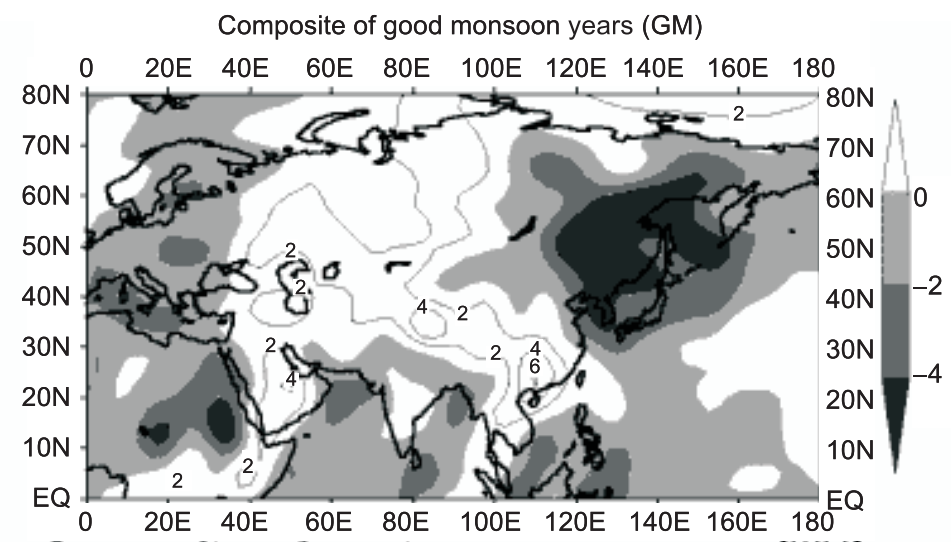

Composite of weak monsoon years (WM)
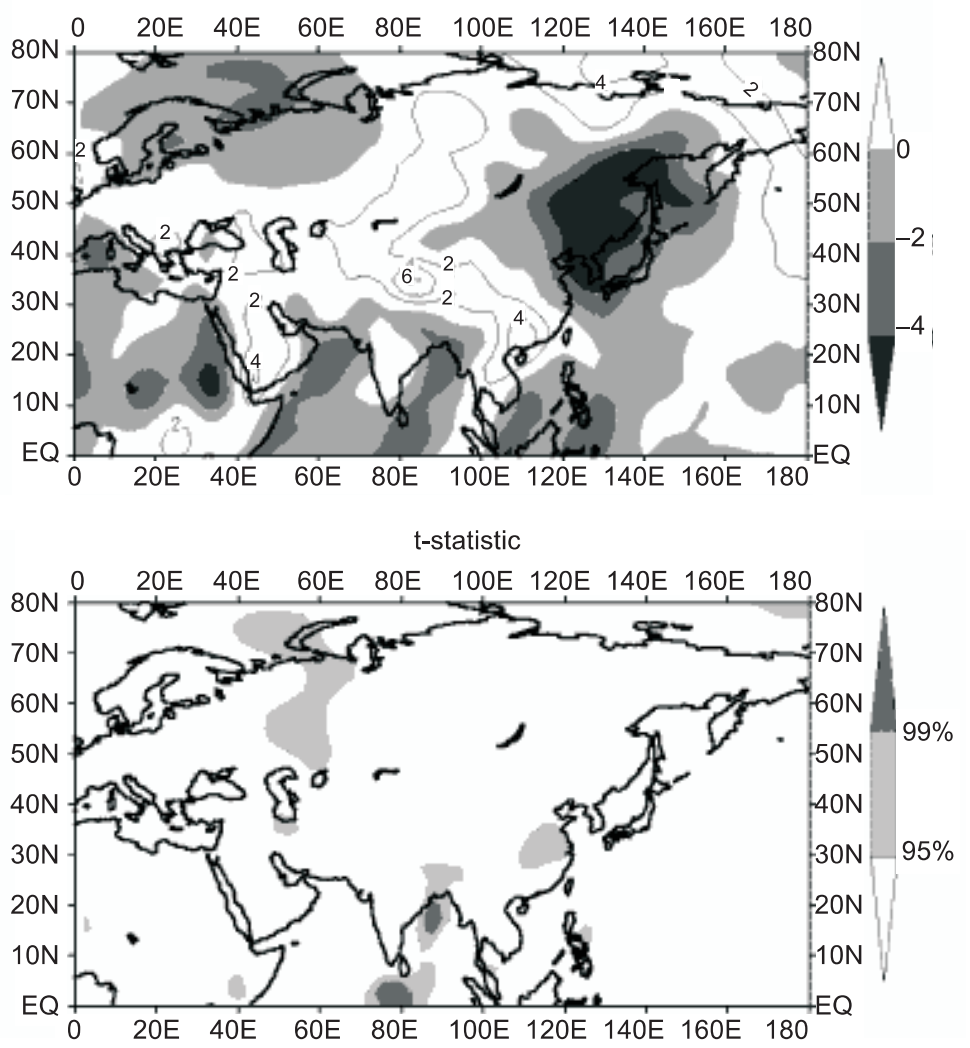

Figure 6. Meridional wind $(v)$ fields for GM and WM and their $t$-statistic at $850 \mathrm{hPa}$ for February (unit: $\mathrm{m} / \mathrm{s}$ ).

in GM chart is replaced by negative $v$ (southward) in WM chart. The $t$-statistic also indicates that the difference in the $v$ wind is statistically significant over the area where the trough axis shifts eastwards. The southward wind through this region might affect the temperature distribution over the central Asia and Indian land mass. This can be verified through temperature anomaly field.

\subsection{Temperature anomaly field}

Temperature anomalies are based on 32 years (1958-1989) mean temperature. Figure 7 gives the temperature anomaly fields for GM and WM along with $t$-statistic. The shaded (unshaded) area represents negative (positive) anomalies. The positive anomalies over north Russia in GM chart are replaced by large negative anomalies in WM chart, indicating the extensive cooling of north Russia during the winter before the weak monsoon. The negative anomalies are indicative of larger snow accumulation over Eurasia. Kripalani and Kulkarni (1999) investigated the interaction of snow depth over Eurasia and AISMR by using snow depth data from 1881-1985. They found that the wintertime snow depth over western Eurasia surrounding Moscow (eastern Eurasia in central Siberia) shows 

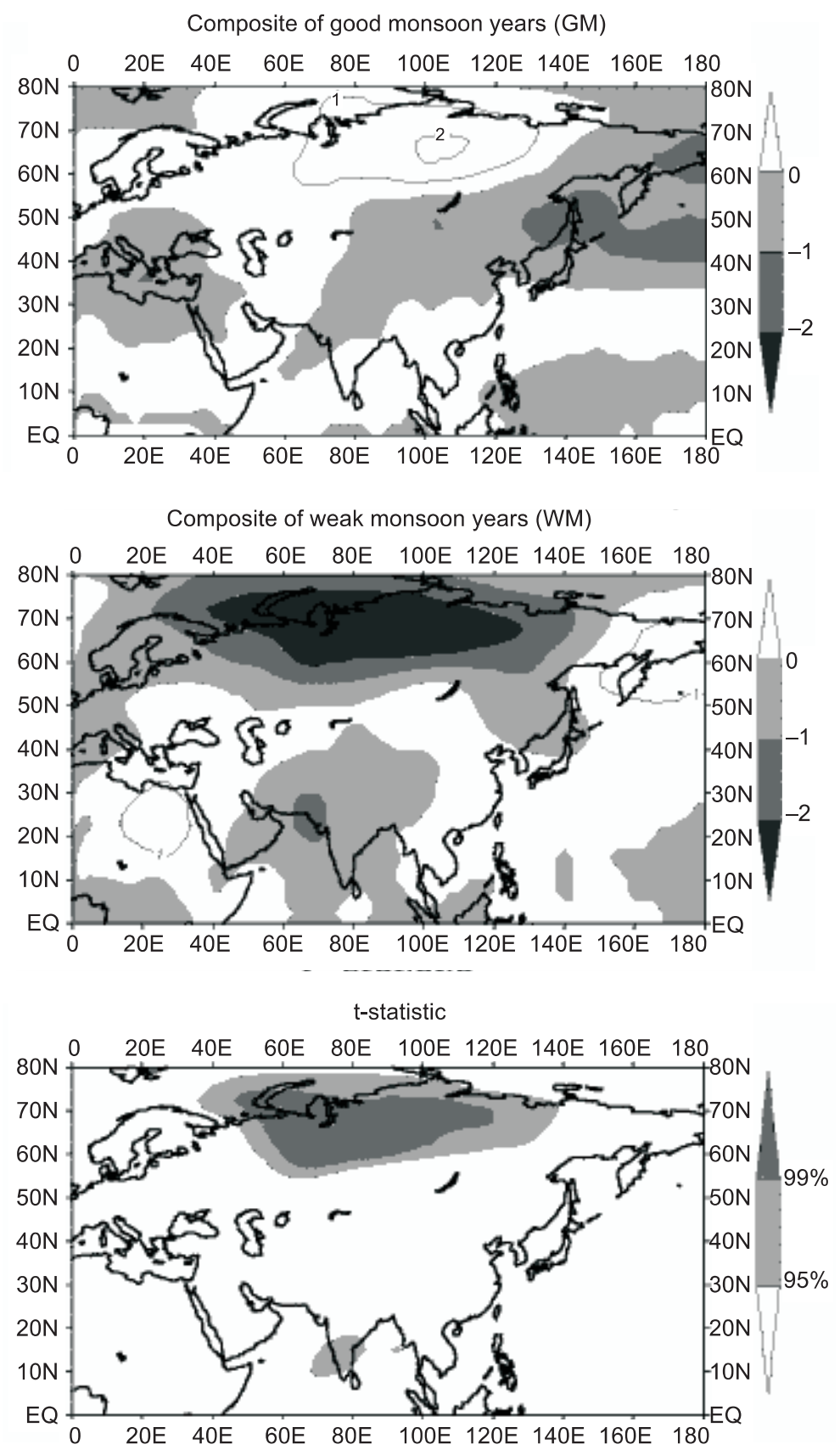

Figure 7. Temperature anomaly fields for GM and WM and their $t$-statistic at $850 \mathrm{hPa}$ for February (unit: K).

significant negative (positive) relationship with subsequent AISMR. Shukla (1987) hypothesized that an excessive snow accumulation in winter can delay the build up of the monsoonal temperature gradient. Meehl (1994b) suggested that cold air advection (and subsequently cooling surface) prevailing over the Eurasian continent in the winter may be more important than the effect of anomalous snow cover itself.

The other interesting factor is that the positive anomalies over central and peninsular India, Arabian Sea and Bay of Bengal in GM chart are also replaced by negative anomalies in WM chart.
This indicates that Indian land mass, particularly peninsular India, Arabian Sea and Bay of Bengal are anomalously cold during the winter before the weak monsoon. Asnani and Awade (1978) concluded that tropical atmosphere is cooler than normal during drought condition. The $t$-statistic indicates that the temperature difference over the Indian peninsula and Arabian Sea is statistically significant. Banerjee et al (1978) pointed out that the $500 \mathrm{hPa}$ normal ridge position over Indian peninsula in April has westerly sub-tropical regime (cold) to its north and easterly tropical regime (warm) to its south. The southward shift of 

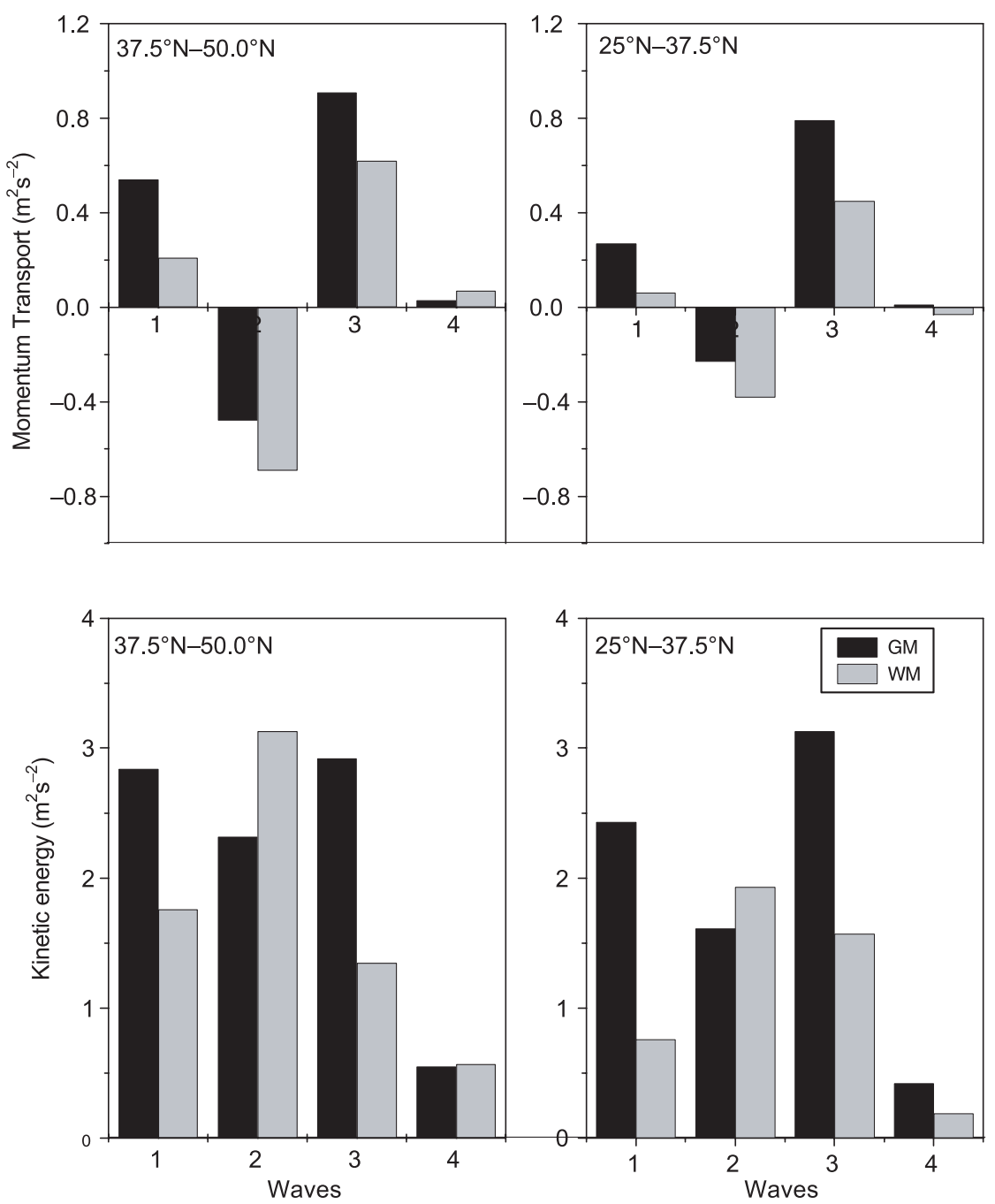

Figure 8. Momentum transport (upper panel) and kinetic energy (lower panel) of waves 1-4 averaged over latitudinal belts from $37.5^{\circ} \mathrm{N}-50^{\circ} \mathrm{N}$ and $25.0^{\circ} \mathrm{N}-37.5^{\circ} \mathrm{N}$ at $850 \mathrm{hPa}$ for February.

the ridge implies that the larger area over the peninsula is under the grip of cold regime.

Heat low over Pakistan, north-south temperature gradient and land-sea temperature contrast are the basic forcings of the Indian summer monsoon. The negative anomalies over the Indian peninsula and Arabian Sea must be delaying and weakening the build up of these forces.

\subsection{Energetics of planetary waves}

It can be seen in figure 5 that the eastward and southward extension of the trough in WM chart is associated with weak circulation pattern to its south and $t$-test indicates that the difference is statistically significant. Fluctuations in the circulation pattern are always captured by the waves and can be quantified through their energetics. Figure 8 gives kinetic energy and momentum transport of waves 1-4 for GM and WM averaged over two latitudinal belts $37.5^{\circ} \mathrm{N}-50^{\circ} \mathrm{N}$ and $25^{\circ} \mathrm{N}-37.5^{\circ} \mathrm{N}$. Northward (positive) momentum transport and kinetic energy of waves 1,3 and 4 over both the belts are weaker for WM. Asnani and Awade (1978) have also observed less momentum transport across $30^{\circ} \mathrm{N}$ by planetary waves during drought conditions and vice versa. The series of kinetic energy and momentum transport of GM and WM are also subjected to student's $t$-test. The $t$-statistic indicates that difference in the kinetic energy and momentum transport of wave 3 over both the belts is significant at $99 \%$ level. The other interesting factor is that the momentum transport by wave 2 is southward over both the belts and more for WM.

\section{Conclusions}

The results of the study indicate that the longitudinal position of the trough around $70^{\circ} \mathrm{N}$ during 
winter influences the performance of subsequent summer monsoon over India and also the energetics of planetary waves over mid latitudes. The eastward and southward shift of this trough from $40^{\circ} \mathrm{E}$ to $70^{\circ} \mathrm{E}$ during February is responsible for southward advection of cold air. Due to this, Russia, Indian land mass (particularly peninsular India), Arabian Sea and Bay of Bengal have significant negative temperature anomalies. Cooler Indian land mass, Arabian Sea and Bay of Bengal during winter might delay and weaken the process of build up of heat low over Pakistan, land-sea temperature contrast and north-south temperature gradient over India. The eastward and southward extension of the trough also weakens the circulation over the mid latitudes, which are very well reflected in the energetics of the planetary waves.

The regression equation between AISMR and kinetic energy is fairly accurate. The negative anomalies of AISMR are very well captured by the regression equation. It is possible to give quantitative prediction of AISMR well in advance.

Apart from the regression equation, the study provides qualitative predictors. The scatter diagram between AISMR and effective kinetic energy of waves 1,3 and 4 indicates that if the kinetic energy is more (less) than $5 \mathrm{~m}^{2} \mathrm{~s}^{-2}$, the subsequent monsoon will be good (weak). The stream function field shows that high latitude trough axis along $40^{\circ} \mathrm{E}\left(70^{\circ} \mathrm{E}\right)$ leads to a good (weak) monsoon over India.

\section{Acknowledgements}

The authors are thankful to Dr. G B Pant, Director, Indian Institute of Tropical Meteorology, Pune for his keen interest in the study and Shri P Seetaramayya, Head, Forecasting Research Division for his encouragement. The authors are also grateful to Prof. Stefan Hastenrath and the anonymous reviewer for their constructive suggestions.

\section{References}

Asnani G C and Awade S T 1978 Monitoring of semipermanent troughs and ridges in relation to monsoon; Indian J. Met. Hydrol. Geophys 29(1\&2) 163-169.

Banerjee A K, Sen P N and Raman C R V 1978 On foreshadowing southwest monsoon rainfall over India with midtropospheric circulation anomaly of April; Indian J. Met. Hydrol. Geophys 29(1\&2) 425-431.

Bawiskar S M and Singh S S 1(1992) Upper tropospheric energetics of standing eddies in wave number domain during contrasting monsoon activity over India; Mausam $\mathbf{4 3}$ 403-410.

Bawiskar S M, Chipade M D and Singh S S 2002a Energetics of lower tropospheric zonal waves during different phases of monsoon; Mausam 53(1) 1-8.

Bawiskar S M, Mujumdar V R and Singh S S 2002b Momentum transport of wave 0 during March: A possible predictor for Indian summer monsoon; Proc. Indian Acad. Sci. (Earth Planet. Sci.) 111 153-162.

Bawiskar S M 2003 Energetics of zonal waves and performance of Indian summer monsoon rainfall; Ph.D. Thesis, University of Pune, p. 201.

Bawiskar S M, Chipade M D, Mujumdar V R and Bhide U V 2005a Contrasting features of wave number one during northern summer monsoon seasons of 1997 and 2002; Mausam 56(2) 337-342.

Bawiskar S M, Chipade M D, Mujumdar V R, Puranik P V and Bhide U V 2005b Kinetic energy of extra tropical waves and their effect on the Indian Monsoon; Mausam 56(3) 681-685.

Kripalani R H and Kulkarni A A 1999 Climatology and variability of historical Soviet snow depth data: Some new perspectives in snow-Indian monsoon teleconnections; Climate Dynamics 15 475-489.

Krishnamurti T N and Kanamitsu M 1981 Northern summer planetary scale monsoon during drought and normal rainfall months; In: Monsoon dynamics (eds) Sir James Lighthill and R P Pearce (Cambridge: University Press) 19-48.

Meehl G A 1994a Coupled ocean-atmosphere-land processes and south Asian monsoon variability; Science 256 263-267.

Meehl G A 1994b Influence of the land surface in the Asian summer monsoon: External conditions versus internal feedbacks; J. Climate 1033-1049.

Shukla J 1987 Interannual variability of monsoon; In: Monsoons (eds) Fein and Stephens (A Wiley Interscience) 399-464. 